\title{
Biological Actions, Electrical Conductance and Silicon-Containing Microparticles of Arsenicum Album Prepared in Plastic and Glass Vials
}

\author{
1 Research Center, Graduating Program of Environmental and \\ Experimental Pathology, Universidade Paulista - UNIP, São Paulo, \\ São Paulo, Brazil \\ ${ }^{2}$ Graduating Program of Animal Medicine and Welfare, Universidade \\ de Santo Amaro - UNISA, São Paulo, São Paulo, Brazil \\ ${ }^{3}$ Faculty of Pharmacy, Universidade Federal do Rio de Janeiro (UFRJ), \\ Rio de Janeiro, Rio de Janeiro, Brazil \\ 4 Farmácia HN Cristiano, São Paulo, São Paulo, Brazil \\ ${ }^{5}$ Graduating Program of History of Science, Pontifícia Universidade \\ Católica de São Paulo, São Paulo, São Paulo, Brazil
}

Luciane Costa Dalboni $^{1}$ Cideli de Paula Coelho ${ }^{1,2}$ Renata Rossettini Palombo Pedro ${ }^{1}$ Michelle Sanchez Correia ${ }^{1}$ Fabiana Rodrigues de Santana ${ }^{1}$ Thayná Neves Cardoso ${ }^{1}$ Sandra Augusta G. Pinto ${ }^{1}$ Anuska M. Alvares-Saraiva ${ }^{1}$ Maristela Dutra-Correa ${ }^{1}$ Giovani B. Peres ${ }^{1}$ Carla Holandino ${ }^{3}$ André Rossi ${ }^{3} \quad$ Amarilys de Toledo César ${ }^{4} \quad$ Silvia Waisse $^{5}$ Leoni Villano Bonamin ${ }^{1}$

Address for correspondence Leoni Villano Bonamin, PhD, Research Center, Graduating Program of Environmental and Experimental Pathology, Universidade Paulista - UNIP, Rua Dr. Bacelar, 1212-4th Floor, São Paulo, SP 04026-002, Brazil (e-mail: leoni.bonamin@docente.unip.br).

Homeopathy 2019;108:12-23.

\begin{abstract}
Keywords

- arsenic

- macrophages

- microparticles

- conductance

- silicon

- homeopathy

Introduction According to the "silica hypothesis" formulated to explain homeopathy, the information of starting materials would be transferred to cells by silica nanoparticles detached from the glassware walls by serial dilution and agitation through epitaxy. We compared the biological activity, electrical current and silicon microparticle content (by means of scanning electron microscopy/energy-dispersive X-ray spectroscopy) of high dilutions (HDs) of arsenic prepared in plastic and glass vials to investigate the role of silica in their biological effects in vitro.

Materials and Methods Co-cultures of macrophages and yeast (Saccharomyces cerevisiae) were treated with different HDs of arsenic prepared in plastic and glass vials. Macrophage morphology, phagocytosis index, nitric oxide (NO), and cytokine production were evaluated.

Results Measurable amounts of silicon microparticles were detected only in the HDs prepared in glass vials, but ultra-centrifugation eliminated them. Specific and nonspecific results were observed. Non-specific pro-inflammatory effects were seen in all dilutions prepared in plastic vials, including elevation of pro-inflammatory cytokines, NO and macrophage phagocytic index. Only the 200th centesimal dilution of arsenic produced specific decrease in interleukin- 6 production in macrophages, and it was independent of the vial type or the presence of microparticles of silica in the medicine samples. The nature of the vials had an impact on the electric flow in the respective fluids.
\end{abstract}

received

June 20, 2017

accepted after revision

August 6, 2018

published online

October 5, 2018
Copyright @ 2019 The Faculty of

Homeopathy
DOI https://doi.org/ 10.1055/s-0038-1670675. ISSN $1475-4916$. 
Conclusion The non-specific, pro-inflammatory effects might be attributed to organic residuals detached from the vials' plastic walls during manipulation. Instead, specific silica-independent effects of the homeopathic medicine can be attributed to the decrease of interleukin- 6 after treatment with the 200th centesimal dilution of arsenic.

\section{Introduction}

Nanoparticles (NPs) of starting materials and contaminants were recently detected in homeopathic high dilutions (HDs) above Avogadro's number. ${ }^{1,2}$ Since homeopathic medicines are traditionally prepared using glass vials, it was postulated that contaminant silica NPs detaching from vials during the step of agitation might represent a critical component involved in the biological effects of these medicines observed experimentally. ${ }^{1-6}$ The understanding of their real effects (specific or non-specific) is crucial to characterize the mechanisms involved.

It is known that nanosilica can form stable three-dimensional structures using DNA, proteins or living cells as template (epitaxial growth). ${ }^{7-13}$ This phenomenon led to a microstructural hypothesis to account for the action of homeopathic medicines. Briefly, nanosilica would behave as non-specific amplifier or vehicle for the specific (structural or electromagnetic) information contained in starting materials, subsequently identified and processed by biological systems. ${ }^{14-16}$ Hypothetically, initial interaction and adsorption of starting material with silica NPs in low homeopathic dilutions would create "nanoseeds" that would be preserved in the preparation of the subsequent dilutions. ${ }^{6,17-19}$ Nanoparticles might also be associated with changes in electrical conductivity, as was shown for the homeopathic medicine Ferrum metalicum, ${ }^{20}$ although other factors can also alter the conductivity of homeopathic aqueous solutions. ${ }^{21}$

Few studies have sought to assess the influence of glass (silica) on the effects of homeopathic HDs. In the pioneer study carried out by Boiron et al, ${ }^{22}$ HDs prepared in paraffincovered glass vials had smaller effect compared with the ones prepared in standard glass vials. One single study investigated trace elements in plastic and glass vials used to prepare and store homeopathic HDs. ${ }^{23}$ The results showed absence of silica in the propylene vials and increase in the concentration of trace elements, mainly silica, lithium and sodium, when bi-distilled water was transferred from propylene to glass vials. The largest difference in trace element concentration occurred in the step from mother tincture to the first centesimal dilution $(1 \mathrm{cH})$; the later steps to $30 \mathrm{cH}$ were not associated with increase in trace element concentration. To the best of our knowledge, no study investigated differences in biological effects between HDs prepared in plastic and glass vials.

Therefore, the aim of the present study was to compare biological effects of homeopathic HDs-Arsenicum album (Ars) $6 \mathrm{cH}$ and $200 \mathrm{cH}-$ prepared in glass and plastic vials to investigate the role of silica microparticles in such effects. The presence of metal microparticles in the drug samples and other relevant physical properties of the solution (electrical conductance) were analyzed. The experimental design and choice of the medicine were based on the literature ${ }^{24}$ and the model chosen, macrophages in co-culture with microorganisms, was previously used in homeopathic fundamental research. ${ }^{25}$ Macrophages are myeloid cells specialized for phagocytosis of micro-organisms, such as yeasts, and stand out for their ability to respond epigenetically to small environmental stimuli, mainly by production of cytokines/chemokines ${ }^{26,27}$ which makes these cells adequate biological sensors in HD research.

\section{Materials and Methods}

\section{High Dilutions}

Homeopathic matrix samples were produced according to the Good Manufacturing Practices at the Pharmacy Faculty of Federal University of Rio de Janeiro, following the Brazilian Homeopathic Pharmacopoeia guidelines. ${ }^{28}$ The starting materials, arsenic and lactose monohydrate, were purchased from Sigma Aldrich $\left(\mathrm{As}_{2} \mathrm{O}_{3}\right.$, batch number BCBD 1149V) and Pharma Nostra Comercial Ltda (Rio de Janeiro, Brazil), respectively.

Arsenic raw material containing 99.984\% and $0.99984 \mathrm{~mol} /$ $\mathrm{mol}^{2}$ of arsenic trioxide, as declared by the supplier, was acquired as a fine powder. The homeopathic manufacturing process followed the statements of Brazilian Homeopathic Pharmacopoeia $^{28}$ and started with the separation of lactose powder in three equal parts. One-third of the lactose was placed in a porcelain vessel to avoid $\mathrm{As}_{2} \mathrm{O}_{3}$ loss. Following this, $\mathrm{As}_{2} \mathrm{O}_{3}$ was added and triturated, meeting the centesimal scale (1 part in 99 parts of inert vehicle), and the complex (Arsenicum album plus lactose) was submitted to two independent and vigorous cycles of crushing and scraping for 20 minutes. After this first cycle, the second and third parts of lactose were added to the porcelain vessel, and submitted to the second and third cycles of crushing and scraping, for 20 minutes each, respectively. The trituration process was concluded at the end of 60 minutes. Each sample received the designation of first triturated $1 / 100$, coded as Arsenicum album 1c. For the second triturated compounding, one part of the first one $(1 \mathrm{cH})$ was mixed in 99 parts of lactose (centesimal scale), and all crushing and scraping procedure repeated to obtain Arsenicum album 2cH. The last trituration process produced Arsenicum album $3 \mathrm{cH}$, following the same protocol described above, using one part of Arsenicum album $2 \mathrm{cH}$ for 99 parts of lactose.

The Arsenicum album $3 \mathrm{cH}$ was used as matrix to the following dynamizations, always according to Brazilian Homeopathic Pharmacopoeia. ${ }^{28}$ HDs were prepared using standard type II amber glass or PET (polyethylene terephthalate, R18/400, Apace, São Paulo, Brazil) vials. The plastic vials were sterilized by microwave heating, three 5 -minute shocks at high intensity. The glass vials were sterilized in an 
autoclave at $121^{\circ} \mathrm{C}$ for 15 minutes. The PET material was silica free, according to the manufacturer.

High dilutions were prepared as follows: centesimal serial dilutions ( 6 for $6 \mathrm{cH}$ and 200 for $200 \mathrm{cH}$ ) were made using different flasks and performing 100 strong vertical motions (agitation) for each dilution. All dilutions were prepared from Ars 3cH using $70 \%$ hydro-alcoholic solution (p/p)-which is equivalent to $77 \%(\mathrm{v} / \mathrm{v})$-in the following steps. A minor deviation of the pharmacopeia guidelines was included to prepare the final working homeopathic dilution, in which sterile water was used: this was necessary to treat single cell cultures without inducing biases related to alcohol concentration of the vehicle and to the possibility of culture contamination. Vertical agitation ("potentization") was performed in each step by means of a mechanical arm used specifically for this purpose (Denise, AUTIC, São Paulo, Brazil). Theoretically, the concentration of Ars $6 \mathrm{cH}$ and Ars $200 \mathrm{cH}$ was $1.3 \times 10^{-11} \mathrm{M}$ and Ars $1.3 \times 10^{-366} \mathrm{M}$, respectively.

Ars $200 \mathrm{cH}$ prepared in glass vials was ultra-centrifuged at $5,000 \mathrm{rpm}$ for 30 minutes to separate heavier particles, and the supernatant alone was analyzed. The tested HDs were designated Ars 6cHP (prepared in plastic vials), Ars 6cHG (prepared in glass vials), Ars 200cHP (prepared in plastic vials), Ars 200cHG (prepared in glass vials), and Ars 200cHGC (prepared in glass vials and centrifuged after). The control was untreated macrophage-yeast co-culture (Control + yeast).

The vials were wrapped with aluminum foil and labeled with a code by a laboratory technician who did not participate in the study (to make the procedures blinded). The investigators were blinded to the vials' content until statistical analysis was completed.

\section{Macrophage-Yeast Culture and Treatments}

RAW 264.7 macrophages were thawed and sown into culture bottles containing RPMI-1640 medium (Cutilab, Brazil) supplemented with $20 \%$ fetal bovine serum and $200 \mathrm{U} \mathrm{mL}^{-1}$ penicillin, $100 \mathrm{U} \mathrm{mL}^{-1}$ streptomycin, and $2.6 \mu \mathrm{g} \mathrm{mL^{-1 }}$ amphotericin B (Cutilab, Campinas, Brazil). Plating was performed in triplicate on six-well plates with $25 \times 10^{5}$ cells per well. Glass slides were not used during plating to keep the cell environment silica-free. Yeast cells (Saccharomyces cerevisiae) were added onto macrophages adhered to the well bottom in proportion 1:10 $\left(25 \times 10^{6}\right.$ yeast cells per well $)$.

The treatment solutions were prepared with pure water filtered in a $0.22 \mu \mathrm{m}$ Millipore filter. The test solutions were added in proportion $20 \%$ to the well volume. A second application of treatments was performed 24 hours later, in proportion $1 \%$. Forty-eight hours after the onset of treatments, the macrophages were fixed with absolute methanol for 15 minutes and subjected to Giemsa staining. This staining method is useful for clear visualization of the yeasts inside the macrophages.

\section{Histomorphometry}

Ten digital photographs were taken per field (NIKON E 200 microscope coupled to Coolpix digital camera, Tokyo, Japan) and 200 cells/well were counted through oil-immersion objective with $100 \times$ magnification. The mean area (pixels) of cells, representing cell spreading, and the percentage of phagocy- tozed yeast cells were counted automatically using the software Metamorph (Molecular Devices; Saint Jose, California, United States). The phagocytic index was calculated as percentage of internalized yeasts to the number of macrophages in each field.

\section{Acridine Orange Test}

The co-cultured cells were incubated after 48 hours of treatment with acridine orange $(5 \mu \mathrm{g} / \mathrm{mL})$ under a $5 \% \mathrm{CO}_{2}$ hood for 20 minutes. Next, the wells were rinsed with phosphate buffered saline (PBS); samples were collected by touching the cells with a slide covered with one drop of PBS, and then examined under fluorescence microscope (Olympus-BX60, Tokyo, Japan) to investigate the lysosome activity. Images were taken with a digital camera coupled to the microscope (Dino-Eye AM7023, New Taipei, Taiwan). In this test, DNAcontaining structures emit green fluorescence, and acid structures, such as lysosomes and phagolysosomes, emit red/ orange fluorescence. Qualitative analysis of cell morphology was performed on serial photomicrographs.

\section{Nitric Oxide Production}

The supernatant from cells kept in co-culture for 48 hours was frozen at $-80^{\circ} \mathrm{C}$ for later measurement of nitrite and nitrate production. Measurement was performed in duplicate by means of the colorimetric method on 96-well plates: to each plate $100 \mu \mathrm{L}$ of supernatant and $100 \mu \mathrm{L}$ of Griess reagent $(0.1 \% \mathrm{~N}$-alpha-naphthyl-ethylenediamine (NED); $1 \%$ sulfanilamide; $2.5 \%$ of phosphoric acid; Sigma-Aldrich, São Paulo, Brazil) were added. A standard curve was plotted starting with the mother solution (140 mg of sodium nitrite [Sigma-Aldrich, São Paulo, Brazil] $+10 \mathrm{~mL}$ of distilled water). The plates were left at room temperature for 10 minutes and then read in enzyme-linked immunosorbent essay spectrophotometer (Thermoplate, TP reader basic, Beijing, China) at $540 \mathrm{~nm}$. The results were assessed by comparing the optical density to the nitric oxide (NO) standard curve and expressed as $\mu$ g of nitrite per $10^{5}$ cells.

\section{Immunoenzymatic Assay for Cytokine Measurement}

Supernatant of the yeast-infected macrophage cultures was collected 48 hours after the onset of treatments, centrifuged at $15,000 \mathrm{rpm}$ for 5 minutes and frozen at $-80^{\circ} \mathrm{C}$ for later cytokine measurement. Cytokines were measured by means to the MAGPIX-Luminex method (kit MILLIPLEX e-Bioscience mouse cytokine Magnet; Darmstadt, Germany) following the manufacturer's instructions. This kit includes detection systems for interferon- $\gamma$, interleukin (IL)- $1 \alpha$, IL-1 $\beta$, IL-6, IL-10, IL-12 (P240), IL-12 (P70), monocyte chemoattractant protein 1 (MCP-1), macrophage inflammatory protein-1 $\beta$ (MIP-1 beta), granulocyte macrophage colony-stimulating factor (GM-CSF), regulated on activation, normal $\mathrm{T}$ cell expressed and secreted chemokine (RANTES), vascular endothelial growth factor (VEGF), and tumor necrosis factor- $\alpha$ (TNF alpha). The samples were analyzed in triplicate and the results expressed as $\mathrm{pg} / \mathrm{mL}$. Samples with values below the limit of detection were recorded as 0 (zero). 


\section{Scanning Electron Microscopy/Energy-Dispersive X-Ray Spectroscopy}

The identification of silicon content in suspended microparticles probably contained in the tested solutions was performed by means of the micro-evaporation method, followed by scanning electron microscopy (SEM) under 10$\mathrm{kV}$ working conditions and by energy-dispersive X-ray spectroscopy (EDX) (JSM 6510; JEOL Ltd, Tokyo, Japan).

Microtubes containing samples of each tested solution were centrifuged at $5,000 \mathrm{rpm}$ for 30 minutes for the microparticles to sediment. A single drop of $10 \mu \mathrm{L}$ was harvested from the bottom of each tube and placed on a stub. The stubs were previously cleansed with $70 \%$ acetone and dried in a closed recipient. The stubs were then kept within a closed Petri dish to ensure that only particles obtained through centrifugation of the tested solutions were analyzed. The drops were left to dry naturally on the stubs up to the time of microscopic analysis. Images were taken with a $10-\mu \mathrm{m}$ scale (see example in - Fig. $\mathbf{1}$ ). The samples were harvested only once from each tube, because in a pilot study we found that the second and third drops were almost particle free.

The results of EDX are expressed as the frequency of silicon among all analyzed microparticles. Thirty-four microparticles deposited on the stubs were randomly chosen for EDX analysis; for samples that did not reach this number, all the deposited particles were analyzed. As the stubs were made of copper, this element was blocked in the reader control to avoid interference. Considering the characteristics of the microscope, to warrant a minimum sensitivity threshold, for each identified element, the percentage of atoms per particle below $1.5 \%$ was considered as zero (negative result).
Thus, traces of other elements (C, O, Na, Mg, Zn, Ca, Be, Nb, Pb, $\mathrm{Cl}, \mathrm{Tc}, \mathrm{Rb}, \mathrm{Al}, \mathrm{S}, \mathrm{Fe}, \mathrm{P}$ ) were randomly detected in all the analyzed dilutions, but, since they were present under the limit of sensitivity of the device, they were not considered.

\section{Electrical Current Flow (Conductance)}

A micro-ammeter (Ryodoraku; São Paulo, Brazil), calibrated to $200 \mathrm{M} / \mathrm{A}$, was used to measure the capacity to allow electric current in each dilution. The device wires were connected to two parallel electrodes $(30 \times 40 \mathrm{~mm})$. The solutions were put into flat cryotubes with parallel walls to avoid contact between the electrodes and the tube wall. ${ }^{29}$ For measurement, the electrodes were inserted $1 \mathrm{~cm}$ into the liquid. The test was performed in three series, in triplicate, at different times of the day, under a closed hood; electronic devices were kept at least $2 \mathrm{~m}$ away from the test site to avoid any influence of magnetic fields. A thermo-hygrometer was placed inside the hood to monitor temperature $\left(24.8^{\circ} \mathrm{C}\right.$, on average) and humidity (57\%). Conductivity was measured after a 5-second interval to allow for stabilization of the device. Pure sterilized water was used as standard for comparison, as its conductivity is quite stable and equal to $100 \mu \mathrm{A}$. Sterilization included autoclaving for 20 minutes followed by filtering through a $22-\mu$ Millipore filter. The vehicle (filtered and agitated 70\% alcohol) was used as experimental control. A sample of water subjected to 100 vertical motions (potentization) was used as supplementary control.

\section{Statistical Analysis}

Statistical analysis was performed using IBM SPSS, version 21.0, and GraphPad Prism, version 6.0, for Windows.

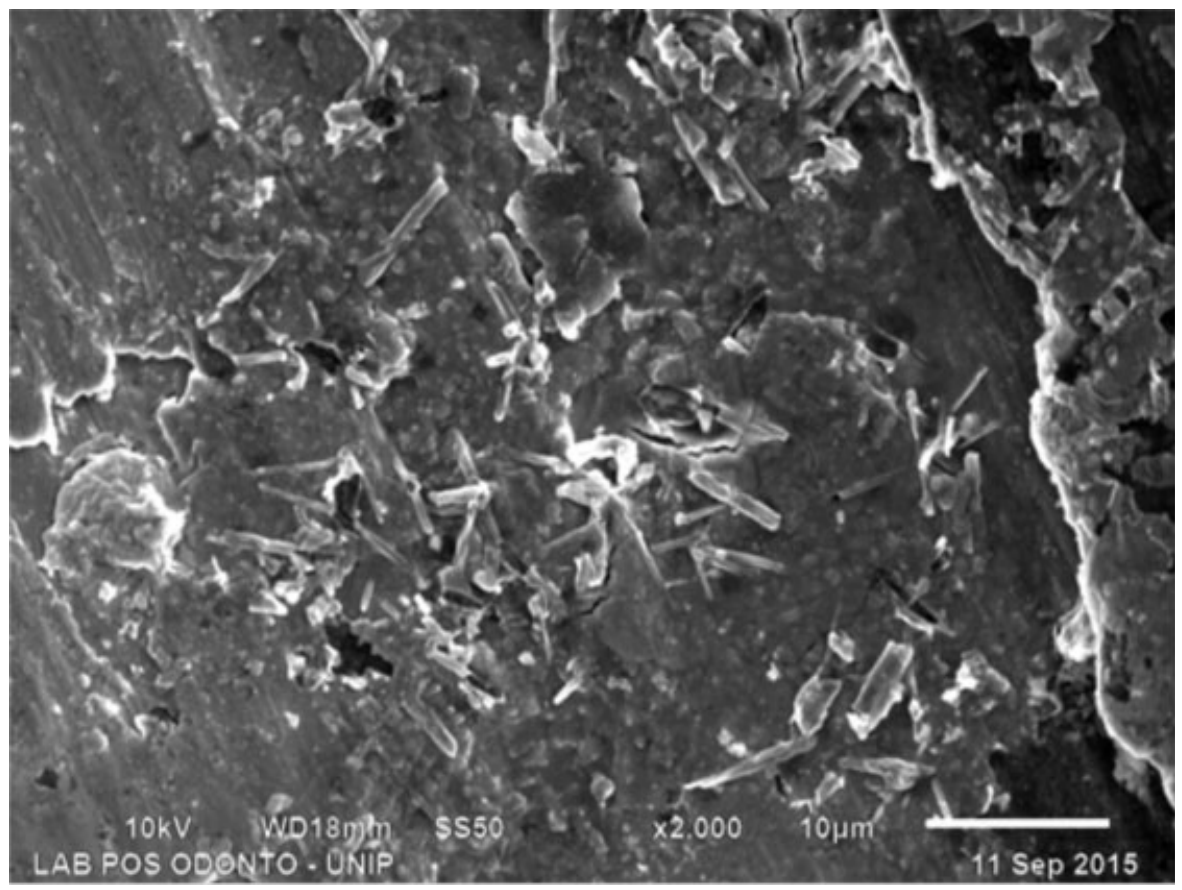

Fig. 1 Scanning electron microscopy (SEM) showing numerous micro-particles deposited on the stub surface. Note that the stub surface is irregular. SEM was used only to identify the presence of silica in the microparticles. Their morphology and size were not evaluated. An illustrative SEM profile showing particles on the stub from a sample of Ars 6cHP is represented. Magnification 2,000x. 
Normality was evaluated by means of the Shapiro-Wilk test and assessed by inspection of quartile-quartile plots (Q-Q plots). Homogeneity of variances was evaluated by Levene's test and the Welch correction was applied to the ANOVA in cases of non-linearity. Outliers were assessed by inspection of $Q-Q$ plots and were removed when necessary.

Outcomes were evaluated by means of two-way ANOVA and Dunnett's post-test. Partial eta-squared $\left(\eta^{2}\right)$, a measure of effect size, was also reported. This parameter was particularly useful for variables presenting large deviation values and analyses with $p$-values that could lead to type I (rejection of a true null hypothesis) or II (retaining a false null hypothesis) errors.

Results are presented as mean \pm standard error and $p$-values $<0.05$ were considered significant.

The profile of the atomic composition of microparticles detected in samples of arsenic dilutions was represented by dot plot graphics with mean and 95\% confidence interval.

\section{Results}

\section{Assessment of In Vitro Spreading, Phagocytosis and Nitric Oxide Production}

On the orange acridine test, Ars 200cHP and Ars 200cHG induced greater lysosomal activity compared with the controls, manifested as patent fluorescent acid vacuoles (- Fig. 2).
Macrophages treated with Ars 200cHP exhibited increased phagocytic index $(p=0.001, F(2,81)=5.638$, $\eta^{2}=0.173$ ) compared with the other groups. Similarly, NO production after 48-hour incubation was higher in Ars 200cHP $\left(p=0.006, F(7,8)=9.199, \eta^{2}=0.775\right)$. However, Ars 200cHG and Ars 200cHGC presented significant reduction in spreading $\left(p=0.001, F(3,60)=11.893, \eta^{2}=0.373\right)$ compared with the control and Ars 200cHP (-Figs. 3 and 4).

Neither Ars 6cHP nor Ars 6cHG induced significant changes in macrophage spreading, phagocytic index or NO production after 48-hour incubation. On the acridine orange test, no significant differences were detected between Ars $6 \mathrm{cH}$ preparations and control (-Figs. 5 and $\mathbf{6}$ ).

\section{Cytokine Measurement}

Interleukin-1 $\beta$ and GM-CSF were not analyzed because the measured values were below the minimum limit of detection as declared by the manufacturer.

Ars $6 \mathrm{cHP}$ induced statistically significant increases in IL- $1 \alpha$ $\left(F(2,6)=15.501 ; p=0.04 ; \eta^{2}=0.838\right)$, IL-6 $(F(2,6)=10.894$ $\left.p=0.010 ; \eta^{2}=0.784\right)$, MCP-1 $(F(2,6)=14.165 ; p=0.005$; $\left.\eta^{2}=0.825\right)$, and VEGF $\left(\mathrm{F}(2,6)=44.335 ; p=0.01 ; \eta^{2}=\right.$ 0.947) (-Fig. 7). In turn, treatment with Ars 200cHP, Ars 200cHG, and Ars 200cHGC was associated with statistically significant reduction in IL-6 $(F(3,8)=4.722 ; p=0.035$; $\left.\eta^{2}=0.639\right)$ compared with the non-treated control (-Fig. 8).
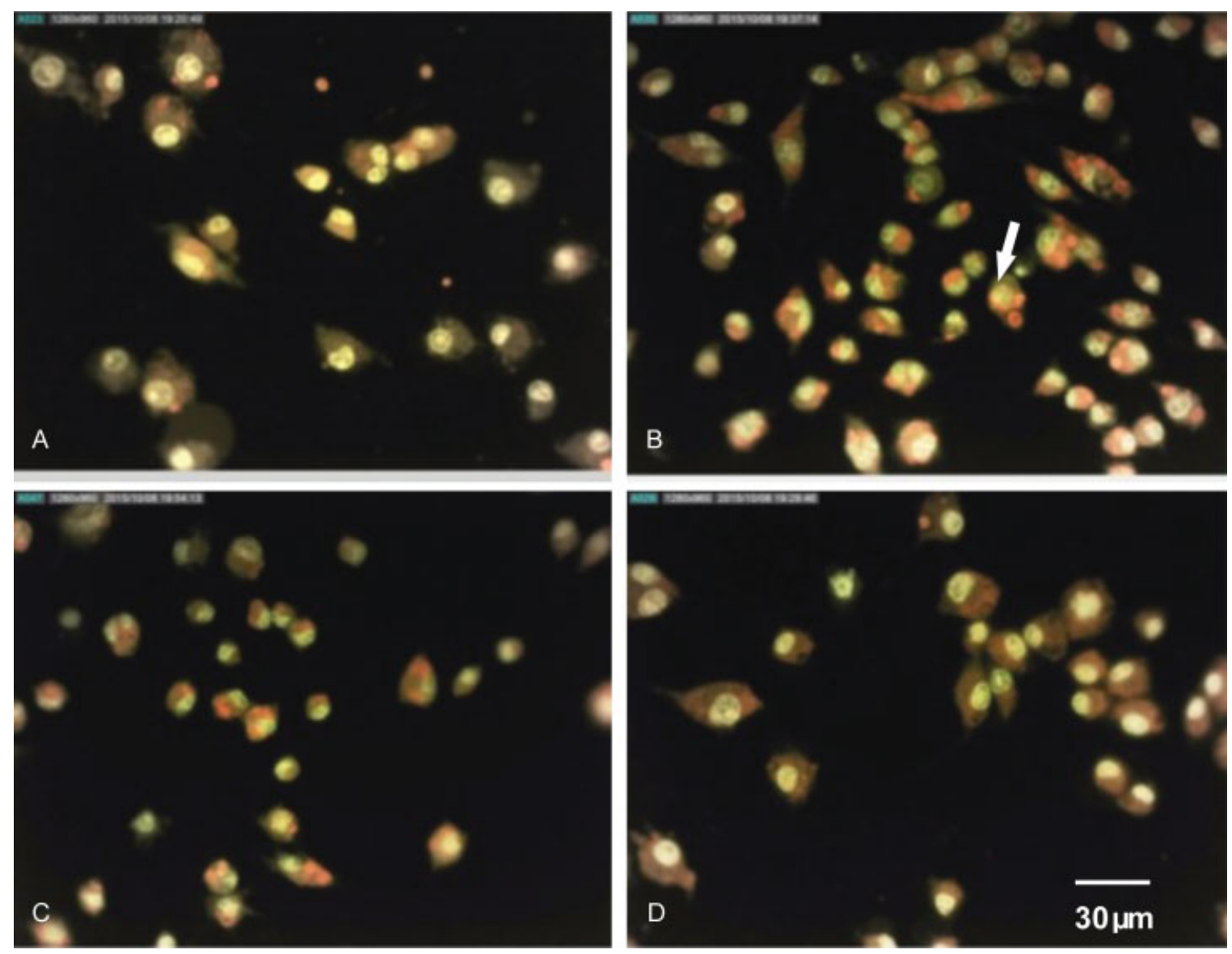

Fig. 2 Photomicrograph of cells stained by means of the acridine orange method under fluorescence microscope. (A) Macrophages co-cultured with yeast. (B) Arsenicum album 200cH prepared in plastic vials. (C) Arsenicum album 200cH prepared in glass vials. (D) Supernatant of centrifuged Arsenicum album 200cH prepared in glass vials. The arrow indicates a phagolysosome with acid content. Magnification 40x. 

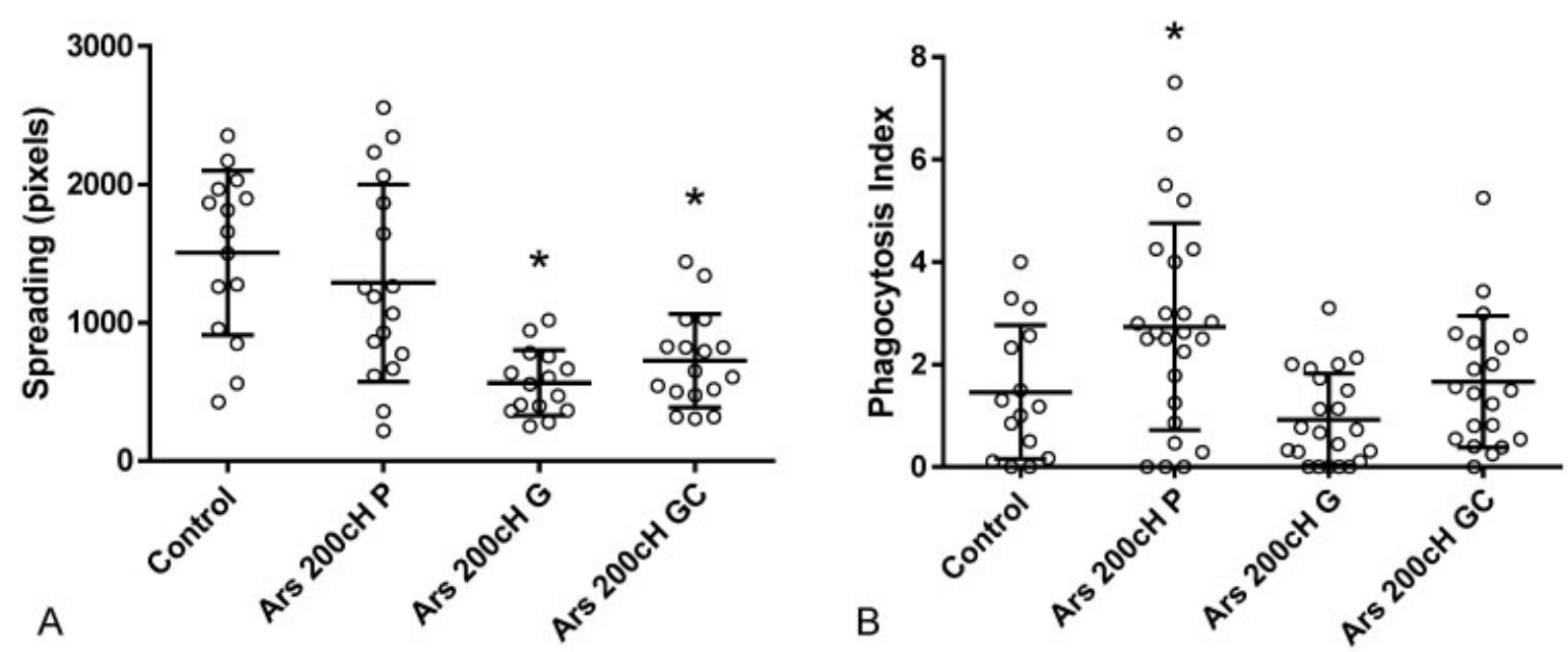

Fig. 3 Spreading (in pixels) (A) and phagocytic index (B) of RAW 264.7 macrophages treated with Arsenicum album 200cH. Values represent individual points, mean and standard error. Control + yeast: macrophage-yeast co-culture. Ars 200cHG: Arsenicum album 200cH prepared in glass vials. Ars 200cHGC: Arsenicum album 200cH prepared in glass vials and centrifuged. Ars 200cHP: Arsenicum album 200cH prepared in plastic vials. (A) "ANOVA, $p<0.001, F(3,60)=11.893, \eta^{2}=0.373$, compared with Ars 200cHP and control; (B) "ANOVA, $p<0.001, F(2,81)=5.638$, $\eta^{2}=0.173$, compared with the other treatments. ANOVA, analysis of variance.

No differences among groups were found regarding the other analyzed cytokines (-Table $\mathbf{1}$ and $\mathbf{2}$ ).

\section{Scanning electron microscopy + energy-dispersive X-ray Particle Analysis}

The presence of measurable silicon among identified particles was only found in Ars 6cHG and Ars 200cHG. No measurable silicon was detected in Ars 200cHP, Ars 200cHGC, and Ars 6cHP (-Table 3).

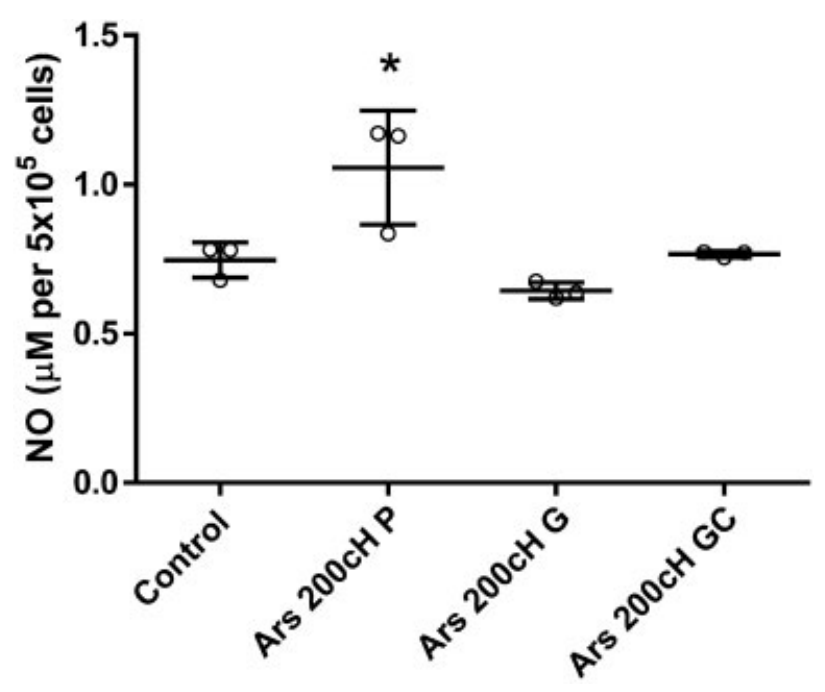

Fig. 4 Nitric oxide $\left(\mu \mathrm{g} / 10^{5}\right.$ cells) in RAW 264.7 macrophage-yeast coculture supernatant after 48-hour incubation. Values represent individual points, mean and standard error. Control + yeast: macrophage-yeast coculture. Ars 200cHG: Arsenicum album 200cH prepared in glass vials. Ars 200cHGC: Arsenicum album 200cH prepared in glass vials and centrifuged. Ars 200cHP: Arsenicum album 200cH prepared in plastic vials. "ANOVA, $p<0.006, F(7,8)=9.199, \eta^{2}=0.775$, compared with the other treatments. ANOVA, analysis of variance.

\section{Electric Current Flow}

The capacity for an electric current to flow in the fluid (conductance) of the pure filtered water was used as a standard for comparison. Significant reduction in electric flow in relation to water was found in $30 \%$ alcohol and Ars 200cHP, probably due to the presence of organic non-polar molecules. Ars $6 \mathrm{cHP}$ also presented low level of conductance, though without statistical significance due to the dispersion of the datapoints. The greatest conductance was exhibited by Ars 200cHGC and Ars 200cHG, in relation to the controls and $\operatorname{Ars} 200 \mathrm{cHP}\left(p=0.001, F(6,95)=134.342, \eta^{2}=0.895\right)$ (-Fig. 9).

\section{Discussion}

The results of the present study show plastic-related nonspecific effects and very specific effects on IL production, which were independent of microparticles containing silicon but probably dependent on the smallest nanostructures, which could include water and the silica itself. In this sense, dilutions of arsenic prepared in plastic vials exhibited proinflammatory effects attributed to putative organic residuals detached from the vials' walls during disinfection and agitation, since these effects were not seen in glass-prepared medicines (-Supplementary Fig. 1, available in the online version only).

Macrophage spreading, phagocytic activity and increase in IL-1 $\alpha$, IL-6, MCP-1, and VEGF in the culture medium were found only in samples treated with medicines prepared in plastic vials-Ars $6 \mathrm{cHP}$ and Ars 200cHP, but not in Ars $6 \mathrm{cHG}$ or Ars 200cHG. These findings suggest that plastic-derived soluble contaminants present in higher potencies might be somehow related to the increase in macrophage activity.

Available evidence indicates that PET bottles subjected to high temperature $\left(40-60^{\circ} \mathrm{C}\right)$ do not exhibit cytotoxic 

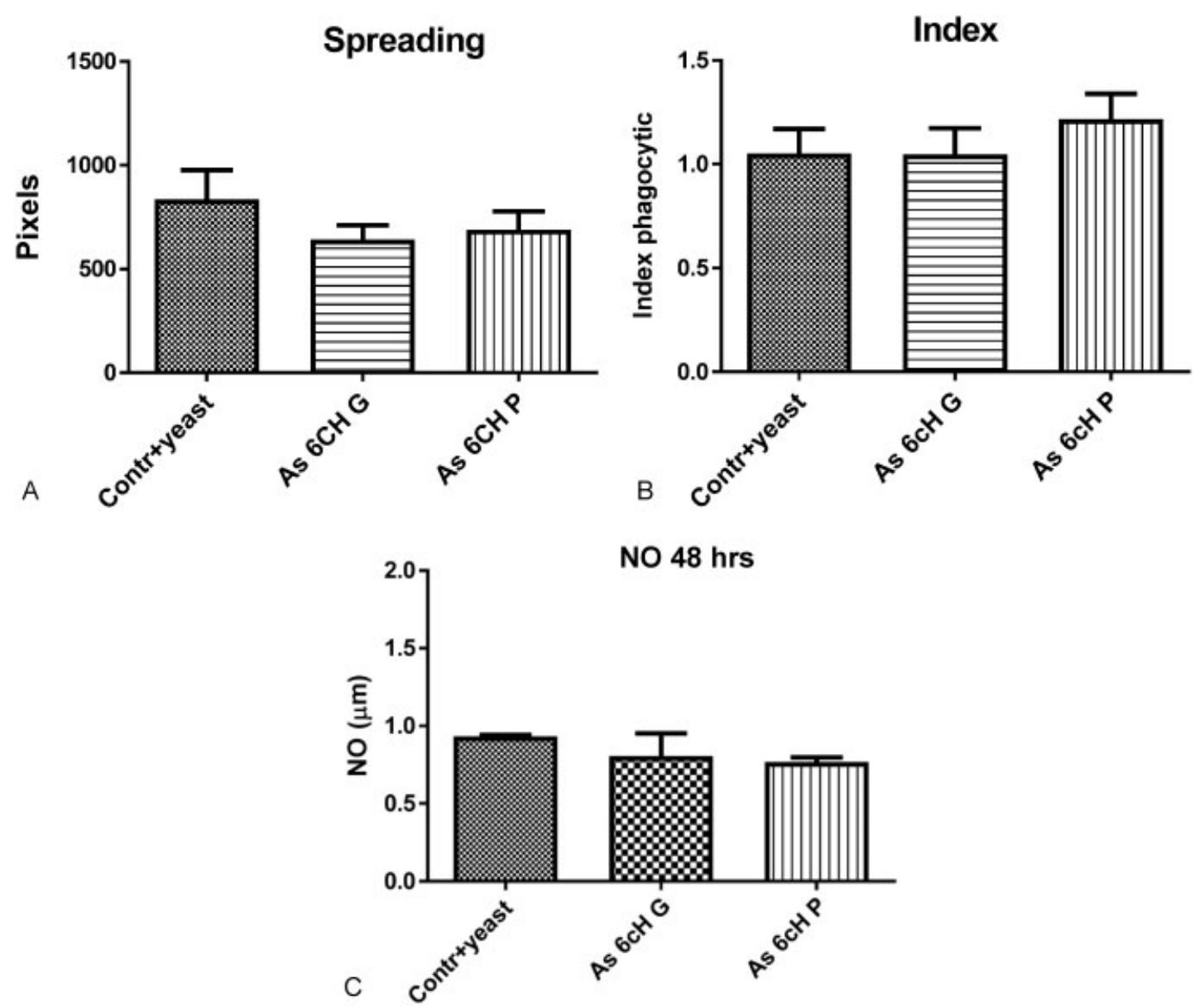

Fig. 5 Spreading (in pixels) (A), phagocytic index (B) and NO production ( $\mu$ g in $10^{5}$ cells) (C) of RAW 264.7 macrophages treated with Arsenicum album $6 \mathrm{cH}$. Values represent mean and standard error. Control + yeast: macrophage-yeast co-culture. Ars 6cHG: Arsenicum album 200cH prepared in glass vials. Ars $6 \mathrm{cHP}$ : Arsenicum album $6 \mathrm{cH}$ prepared in plastic vials. ANOVA, analysis of variance.
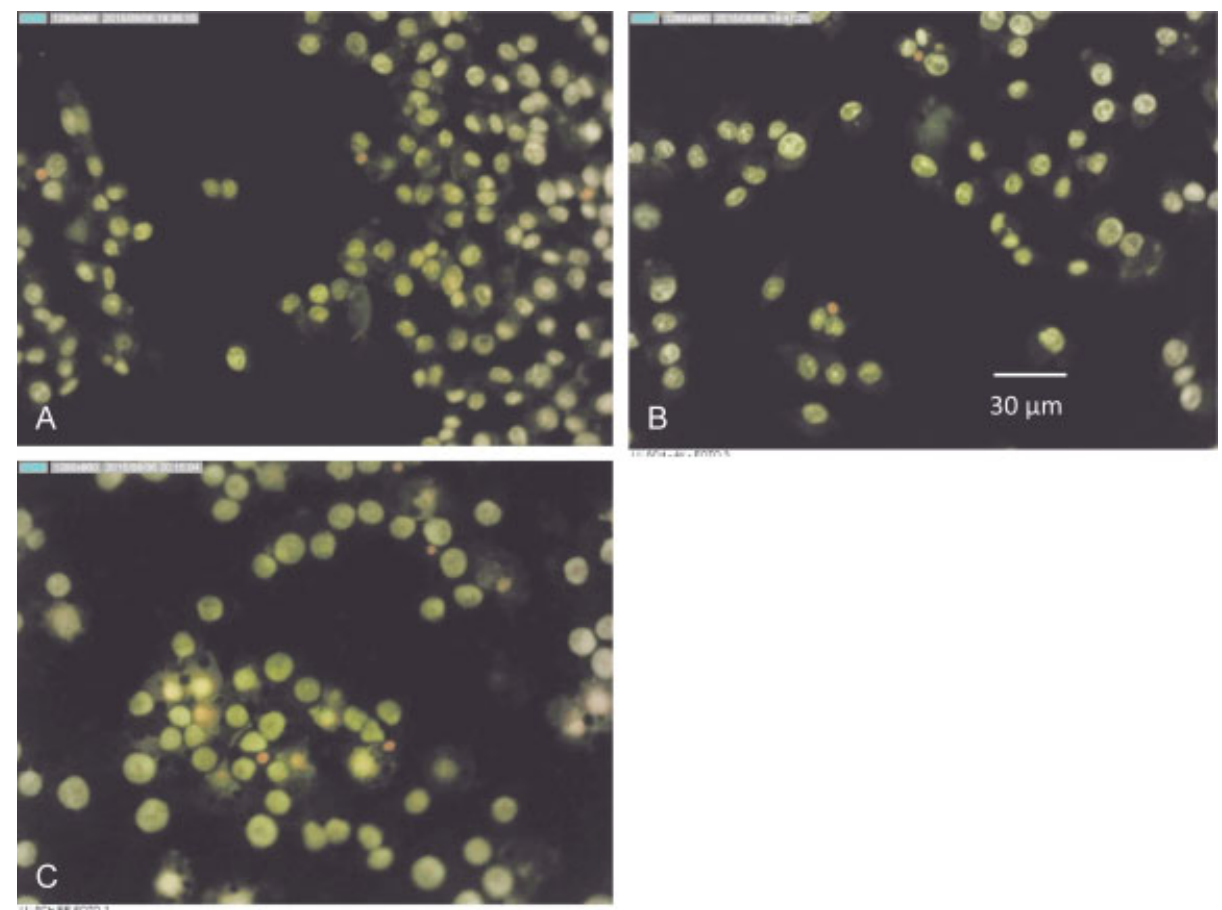

Fig. 6 Photomicrograph of cells stained by means of the acridine orange method under fluorescence microscope. (A) macrophages co-cultured with yeast. (B) Arsenicum album $6 \mathrm{cH}$ prepared in glass vials. (C) Arsenicum album $6 \mathrm{cH}$ prepared in plastic vials. 40x magnification. 

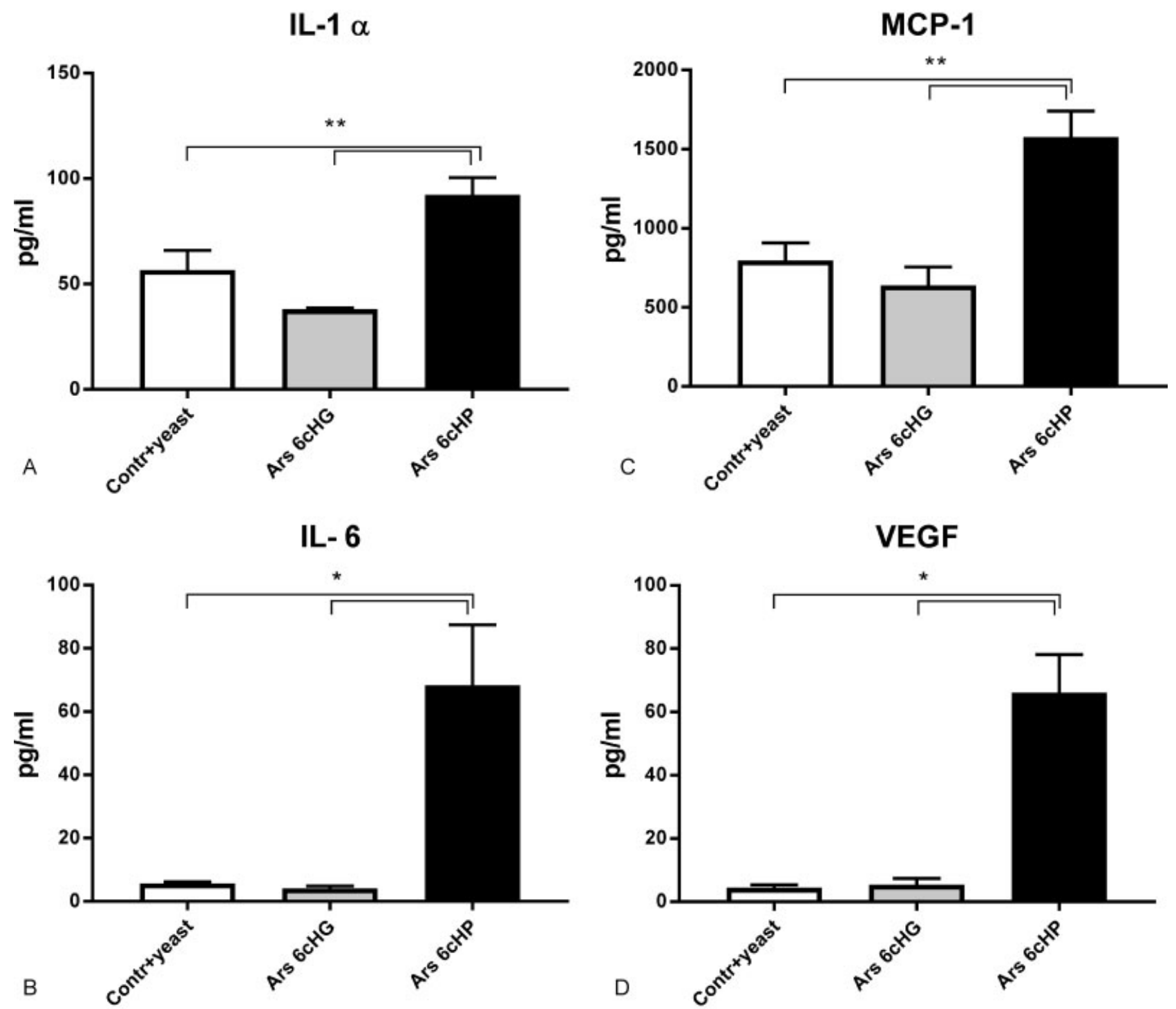

Fig. 7 Concentration (pg/mL) of cytokines and chemokines in the supernatant collected from RAW 264.7-yeast co-culture. IL-1 $\alpha$ (A), IL-6 (B), MCP-1 (C), VEGF (D) produced by cells treated with Arsenicum album $6 \mathrm{cH}$ prepared in glass and plastic vials. Values represent mean and standard error. $p<0.05$ compared with the untreated control, two-way ANOVA. ${ }^{* *} p<0.005$ compared with the untreated control, two-way ANOVA. See text for $\eta^{2}$ values. ANOVA, analysis of variance; IL-1 $\alpha$, interleukin-1 $\alpha$; MCP-1, monocyte chemoattractant protein-1; VEGF, vascular endothelial growth factor.

activity, ${ }^{30}$ but biomaterials containing PET might modify the macrophage activity in vitro. ${ }^{31,32}$ In any case, plastic components have relevant biological actions, this fact being of interest for homeopathic pharmaceutics and, thus, deserving of more thorough study. For instance, one study compared homeopathic medicine Gelsemium sempervirens $6 c, 30 c$, and 200 c to agitated vehicle controls (6c, 30c, and 200c) and nonagitated solvent prepared in vials with natural cork stoppers and with silicone stoppers. All the vials with cork stoppers exhibited more than $4 \times 10^{8} \mathrm{NPs} / \mathrm{mL}$, significantly more than with the non-agitated silicone stoppers. On ultraviolet-visible spectroscopy, the agitated control 30c exhibited significantly higher absorbance, while the non-agitated silicone stopper controls had significantly lower mean absorbance than all the other samples. $^{33}$

These findings suggest that the agitation inherent to homeopathic remedy manufacture released trace materials from natural cork stoppers that could interfere with various properties of HDs, and eventually also with their biological activity. ${ }^{33}$ Also, potentized water exhibited a residual effect on macrophage spreading, which might be attributed to a non-specific action of micro- and/or nano-bubbles. ${ }^{34} \mathrm{~A}$ direct action of medicines on yeast is unlikely in the present case because, according to the literature, treatment with Ars in decimal dilutions $8 x$ and $16 x$ did not induce any change in S. cerevisiae growth. ${ }^{35}$

The decrease in IL-6 production might be considered as the main specific biological effect of Arsenicum album $200 \mathrm{cH}$, since it was observed not only in this potency but in all situations: Ars 200cHG, Ars 200cHGC, and Ars 200cHP. Therefore, these specific effects were not related to the identification of silicon-containing microparticles and agree with the effects of Ars $200 \mathrm{cH}$ on leukocytes previously described. ${ }^{24}$ The decrease in macrophage spreading after 


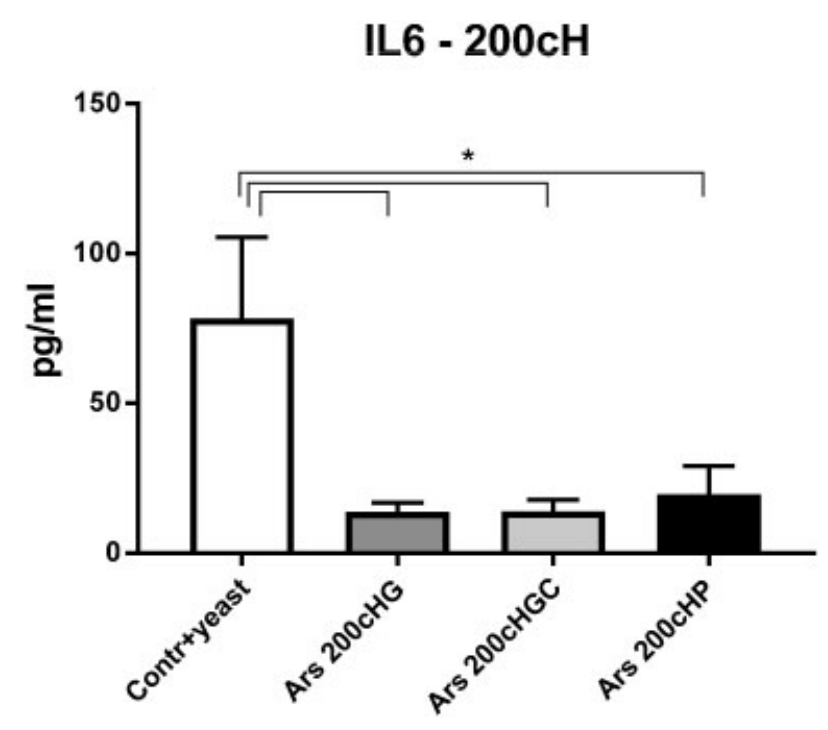

Fig. 8 Concentration $(\mathrm{pg} / \mathrm{mL})$ of IL-6 in the supernatant collected from RAW 264.7-yeast co-culture treated with Arsenicum album $200 \mathrm{cH}$ prepared in glass (centrifuged or not) and plastic vials. Values represent mean and standard error. $p=0.035$ compared with the untreated control, two-way ANOVA. See text for $\eta^{2}$ values. ANOVA, analysis of variance; IL-6, interleukin-6.

treatment with Ars 200cHG and Ars 200cHGC corroborates this result; besides it is very specific, focused on the reduction in IL-6 production itself. This specific feature is also seen in other studies involving gene expression and homeopathy. $27,36,37$

The acridine orange test showed an interesting result. While Ars 200cHP and Ars 200cHG induced a similar mor- phological pattern, characterized by patent acid vacuoles (lysosomes), Ars 200cHGC (superficial phase after centrifugation) induced a less active pattern. Maybe the ultracentrifugation of Ars 200cHG and the resulting changes in its microparticle composition can be related to this result, since the biggest particles present before centrifugation could also be phagocytosed, stimulating the cells. ${ }^{38-41}$

The correlation between electric current flow through the liquids and the type of the vial used corroborates the hypothesis in which metal particles in suspension could improve conductivity ${ }^{1,2,21,41}$ and possible organic contaminants from plastic could impair it. The size of these particles seems not to be important in this case, since Ars 200cHGC (only the supernatant of the medicine, after ultra-centrifugation) presented the highest values of electric current flow.

In short, the results of the present study indicate lack of correlation between the presence of silicon-containing microparticles and biological (specific or non-specific) effects of the tested HDs. On these grounds, one might not infer that silicon-containing microparticles could carry the information of homeopathic medicines to biological systems. However, smaller particles, as NPs, ${ }^{1,2,4-6,22,32,33}$ might explain the divergence. Moreover, in this model, NPs of the original substance could not be observed, maybe due to the limitations of the microscope used. Some studies showing these particles and their putative hormetic effects are well described in the literature. ${ }^{41-43}$

Another hypothesis remains to be checked in the future: that the capacity of water itself acts as information carrier, based on electromagnetic properties derived from its dipole behavior. $^{44-48}$ Alternatively, the participation of both elements together-water and particles, mixed in complex

Table 1 Cytokines, chemokines and VEGF-A measurements $(\mathrm{pg} / \mathrm{mL})$ in the supernatant of macrophages treated with different protocols of Arsenicum album. The supernatants were harvested after 48 hours of culture and treatment. Values are expressed in mean and standard deviation. Experiment using Arsenicum album $6 \mathrm{cH}$

\begin{tabular}{|l|l|l|l|}
\hline Treatments & Untreated control & Ars 6cHG & Ars 6cHP \\
\hline INF- $\gamma$ & $4.55 \pm 1.19$ & $4.69 \pm 0.73$ & $4.11 \pm 0.97$ \\
\hline IL-1 $\alpha$ & $56.64 \pm 16.03$ & $38.04 \pm 1.15$ & $92.34 \pm 13.95^{* *}$ \\
\hline IL-6 & $5.68 \pm 0.95$ & $4.16 \pm 1.25$ & $68.25 \pm 33.20^{*}$ \\
\hline IL-10 & $3.61 \pm 1.25$ & $3.27 \pm 0.39$ & $3.98 \pm 0.66$ \\
\hline IL-12 p40 & $6.01 \pm 2.30$ & $4.63 \pm 0.74$ & $4.98 \pm 0.95$ \\
\hline IL-12 p70 & $10.86 \pm 9.53$ & $4.53 \pm 1.22$ & $5.42 \pm 2.18$ \\
\hline MCP-1 & $795.33 \pm 193.08$ & $638.66 \pm 202.74$ & $1576.33 \pm 286.19^{* *}$ \\
\hline MIP-1 $\beta$ & $12727.00 \pm 768.09$ & $12647.33 \pm 494.54$ & $13796.33 \pm 643.12$ \\
\hline RANTES & $261.33 \pm 58.52$ & $262.00 \pm 75.43$ & $352.66 \pm 104.57$ \\
\hline VEGF & $4.48 \pm 1.53$ & $5.46 \pm 3.28$ & $66.08 \pm 17.02^{*}$ \\
\hline TNF- $\alpha$ & $890.66 \pm 139.95$ & $760.00 \pm 113.84$ & $714 \pm 65.50$ \\
\hline
\end{tabular}

Abbreviations: IL-1 $\alpha$, interleukin- $1 \alpha$; INF- $\gamma$, interferon- $ү$; MCP-1, monocyte chemoattractant protein-1; MIP-1 $\beta$, macrophage inflammatory protein$1 \beta$; RANTES, regulated on activation, normal T cell expressed and secreted chemokine; TNF- $\alpha$, tumor necrosis factor- $\alpha$; VEGF, vascular endothelial growth factor.

${ }^{*} p<0.05$ compared with the untreated control,

${ }^{* *} p=0.005$ compared with the untreated control, two-way ANOVA.

See text for $\eta^{2}$ values. 
Table 2 Cytokines, chemokines and VEGF-A measurements $(\mathrm{pg} / \mathrm{mL})$ in the supernatant of macrophages treated with different protocols of Arsenicum album. The supernatants were harvested after 48 hours of culture and treatment. Values are expressed in mean and standard deviation. Experiment using Arsenicum album $200 \mathrm{cH}$

\begin{tabular}{|l|l|l|l|l|}
\hline Treatments & Untreated control & Ars 200cHG & Ars 200cHGC & Ars 200cHP \\
\hline INF- $\gamma$ & $4.75 \pm 1.36$ & $3.96 \pm 1.09$ & $5.08 \pm 1.47$ & $4.75 \pm 1.50$ \\
\hline IL-1 $\alpha$ & $77.70 \pm 71.27$ & $82.06 \pm 70.67$ & $48.02 \pm 42.20$ & $71.71 \pm 39.02$ \\
\hline IL-6 & $78.48 \pm 46.63$ & $13.78 \pm 5.22^{*}$ & $13.96 \pm 35.77^{*}$ & $19.56 \pm 31.49^{*}$ \\
\hline IL-10 & $4.00 \pm 0.94$ & $4.36 \pm 1.55$ & $3.61 \pm 1.27$ & $3.81 \pm 1.22$ \\
\hline IL-12 p40 & $4.85 \pm 1.42$ & $4.89 \pm 1.80$ & $4.28 \pm 1.46$ & $4.22 \pm 1.42$ \\
\hline IL-12 p70 & $7.86 \pm 3.63$ & $6.06 \pm 4.21$ & $6.39 \pm 2.55$ & $6.84 \pm 2.37$ \\
\hline MCP-1 & $3237.00 \pm 1574.47$ & $1453.00 \pm 940.16$ & $1985.33 \pm 1111.32$ & $1742.66 \pm 1053.59$ \\
\hline MIP-1 $\beta$ & $14675.33 \pm 1302.98$ & $13161.67 \pm 1685.76$ & $14763.33 \pm 4743.15$ & $13758.33 \pm 4577.11$ \\
\hline RANTES & $230.00 \pm 118.82$ & $121.97 \pm 84.36$ & $114.12 \pm 80.16$ & $157.50 \pm 82.97$ \\
\hline VEGF & $8.39 \pm 6.61$ & $8.31 \pm 3.90$ & $8.19 \pm 3.30$ & $5.88 \pm 3.13$ \\
\hline TNF- $\alpha$ & $1765.00 \pm 474.00$ & $1345.66 \pm 509.48$ & $1448.33 \pm 502.74$ & $1536.33 \pm 557.24$ \\
\hline
\end{tabular}

Abbreviations: ANOVA, analysis of variance; IL-1 $\alpha$, interleukin-1 $\alpha$; INF- $\gamma$, interferon- $\gamma$; MCP-1, monocyte chemoattractant protein-1; MIP-1 $\beta$, macrophage inflammatory protein-1 $\beta$; RANTES, regulated on activation, normal T cell expressed and secreted chemokine; TNF- $\alpha$, tumor necrosis factor- $\alpha$; VEGF, vascular endothelial growth factor.

${ }^{*} p=0.035$ compared with the untreated control, two-way ANOVA.

$\eta^{2}=0.639$.

nano-structures that are almost impossible to separate in nature-could elicit some biological effect. ${ }^{49}$

Many studies using refined methods are still needed to establish which hypotheses account for the mechanism of action of homeopathy, since several rationales represent reasonable possibilities. ${ }^{50,51}$

\section{Conclusions}

Homeopathic Arsenicum album in both potencies, $6 \mathrm{cH}$ and $200 \mathrm{cH}$, can induce changes in conductivity and biological effects on macrophages according to the type of vial used (plastic or glass). Non-specific plastic-related pro-inflammatory effects were seen in both potencies of Arsenicum album prepared in plastic vials. Specific antiinflammatory effect was seen for Arsenicum album $200 \mathrm{cH}$, by its reduction in IL- 6 whatever the kind of vial used and the presence or absence of silicon-containing microparticles. However, the participation of smaller particles (NPs) and/or other physico-chemical properties of water remains to be determined.

Table 3 Frequency of the element silicon among the identified micro-particles found in different Arsenicum album samples, using SEM/EDX system (number of particles "positive" to the presence of silicon in relation to the total)

\begin{tabular}{|l|l|l|l|l|l|}
\hline Frequency & $\begin{array}{l}\text { Ars } \\
\text { 6cHG }\end{array}$ & $\begin{array}{l}\text { Ars } \\
\text { 6cHP }\end{array}$ & $\begin{array}{l}\text { Ars } \\
\text { 200cHG }\end{array}$ & $\begin{array}{l}\text { Ars } \\
\text { 200cHGC }\end{array}$ & $\begin{array}{l}\text { Ars } \\
\text { 200cHP }\end{array}$ \\
\hline Per particle & $3 / 34$ & $0 / 24$ & $3 / 34$ & $0 / 13$ & $0 / 24$ \\
\hline Percentage & $8.8 \%$ & $0 \%$ & $12.5 \%$ & $0 \%$ & $0 \%$ \\
\hline
\end{tabular}

Abbreviations: EDX, energy-dispersive X-ray spectroscopy; SEM, scanning electron microscopy.
Highlights

- Arsenicum album $200 \mathrm{cH}$ decreases specifically IL-6 expression in macrophages in vitro.

- Silicon content in microparticles found in Arsenicum album has no relation to specific biological effects.

- Remedies prepared in plastic vials presented non-specific pro-inflammatory action.

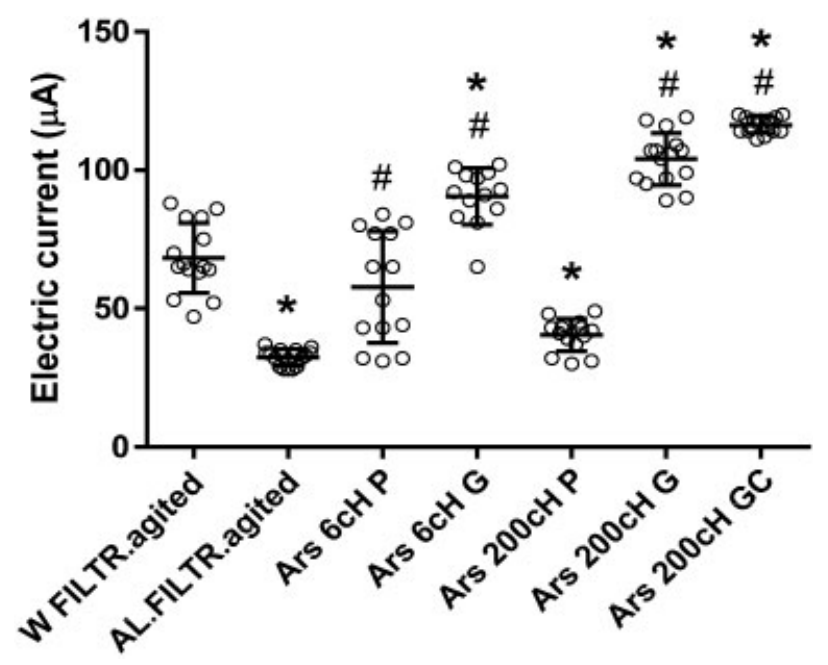

Fig. 9 Electrical current flow (conductance) of arsenic HDs $(\mu \mathrm{A})$. Values represent individual points, mean and standard error. W FILTR agitated: pure water filtered in a 22- $\mu \mathrm{m}$ filter (Millipore) and vertically agitated (100 times). AL FILTR agitated: 70\% alcohol filtered in 22- $\mu \mathrm{m}$ filter (Millipore) and vertically agitated (100 times). Ars 6cHG: Arsenicum album 6cH prepared in glass vials. Ars $6 \mathrm{cHP}$ : Arsenicum album $6 \mathrm{cH}$ prepared in plastic vials. Ars 200cHG: Arsenicum album 200cH prepared in glass vials. Ars 200cHGC: Arsenicum album 200cH prepared in glass vials and centrifuged. Ars 200cHP: Arsenicum album $200 \mathrm{cH}$ prepared in plastic vials. ANOVA, $F(6$, $95)=134.342, \eta 2=0.895 ; " p<0.001$ in relation to water; ${ }^{* *} p<0.001$ in relation to the other treatments. 
- Decrease in IL-6 was independent of the material of the vials and/or of the silica microparticle content.

- The nature of the vials seems to influence the electric flow in the respective fluids.

\section{Supplementary Files}

-Supplementary Fig. 1 Flow-chart of the study design and the main results.

\section{Funding}

We thank the Brazilian Association of Homeopathic Pharmacists (Associação Brasileira de Farmacêuticos Homeopatas-ABFH) for funding the study and CAPES-PROSUP (number 1678566) for the PhD grant.

\section{Conflict of Interest}

The authors declare there is no conflict of interest. Funding sponsors did not interfere with the design of the study, collection, analysis or interpretation of data, manuscript writing, or with the decision to publish the results. The initial project was selected for ABFH grant after ad hoc and blind evaluation of the proposal.

\section{Acknowledgments}

We would like to thank Fabiana Toshie Konno for her technical support and Prof. Dorly Buchi and Elizabeth C P Hurtado for the training in macrophage manipulation.

\section{References}

1 Chikramane PS, Suresh AK, Bellare JR, Kane SG. Extreme homeopathic dilutions retain starting materials: a nanoparticulate perspective. Homeopathy 2010;99:231-242

2 Rajendran ES. Homeopathy a material science! nanoparticle characterization of Aurum metallicum 6C, 30C, 200C, 1000C, 10000C, 50000C and 100000C. Int J Curr Res 2017;9:48923-48927

3 Bhattacharyya SS, Mandal SK, Biswas R, et al. In vitro studies demonstrate anticancer activity of an alkaloid of the plant Gelsemium sempervirens. Exp Biol Med(Maywood)2008;233:1591-1601

4 Ives JA, Moffett JR, Arun P, et al. Enzyme stabilization by glass-derived silicates in glass-exposed aqueous solutions. Homeopathy 2010;99:15-24

5 Demangeat JL. NMR relaxation evidence for solute-induced nanosized superstructures in ultramolecular aqueous dilutions of silica-lactose. J Mol Liq 2010;155:71-79

6 Upadyhay RP, Nayak C. Homeopathy emerging as nanomedicine. Int J High Dilution Res. 2011;10:299-310

7 Perry CC, Tucker TK. Crystalline silica prepared at room temperature from aqueous solution in the presence of intrasilica bioextracts. Chem Commun (Camb) 1998;23:2587-2588

8 Perry CC, Tucker TK. Model studies of colloidal silica precipitation using biosilica extracts from Equisetum telmateia. Colloid Polym Sci 2003;281:652-664

9 Khripin CY, Pristinski D, Dunphy DR, Brinker CJ, Kaehr B. Proteindirected assembly of arbitrary three-dimensional nanoporous silica architectures. ACS Nano 2011;5:1401-1409

10 Wang DC, Chen GY, Chen KY, Tsai CH. DNA as a template in self-assembly of Au nano-structure. IET Nanobiotechnol 2011; 5:132-135
11 Baca HK, Carnes EC, Ashley CE, et al. Cell-directed-assembly: directing the formation of nano/bio interfaces and architectures with living cells. Biochim Biophys Acta 2011;1810:259-267

12 Neville F, Broderick MJ, Gibson T, Millner PA. Fabrication and activity of silicate nanoparticles and nanosilicate-entrapped enzymes using polyethyleneimine as a biomimetic polymer. Langmuir 2011;27:279-285

13 Bhattacharyya SS, Das J, Das S, et al. Rapid green synthesis of silver nanoparticles from silver nitrate by a homeopathic mother tincture Phytolacca Decandra. Zhong Xi Yi Jie He Xue Bao 2012; 10:546-554

14 Anick DJ, Ives JA. The silica hypothesis for homeopathy: physical chemistry. Homeopathy 2007;96:189-195

15 Hornung V, Bauernfeind F, Halle A, et al. Silica crystals and aluminum salts activate the NALP3 inflammasome through phagosomal destabilization. Nat Immunol 2008;9:847-856

16 Xynos ID, Edgar AJ, Buttery LDK, Hench LL, Polak JM. Ionic products of bioactive glass dissolution increase proliferation of human osteoblasts and induce insulin-like growth factor II mRNA expression and protein synthesis. Biochem Biophys Res Commun 2000;276:461-465

17 Holandino C, Oliveira AP, Homsani F, et al. Structural and thermal analyses of zinc and lactose in homeopathic triturated systems. Homeopathy 2017;106:160-170

18 Caron V, Willart JF, Lefort R, Derollez P, Danède F, Descamps M. Solid state amorphization kinetic of alpha lactose upon mechanical milling. Carbohydr Res 2011;346:2622-2628

19 Das S, Das J, Samadder A, Bhattacharyya SS, Das D, Khuda-Bukhsh AR. Biosynthesized silver nanoparticles by ethanolic extracts of Phytolacca decandra, Gelsemium sempervirens, Hydrastis canadensis and Thuja occidentalis induce differential cytotoxicity through G2/M arrest in A375 cells. Colloids Surf B Biointerfaces 2013;101:325-336

20 Paul BK, Kar S, Bandyopadhyay P, et al. Significant enhancement of dielectric and conducting properties of electroactive polymer polyvinylidene fluoride films: an innovative use of Ferrum metallicum at different concentrations. Indian J Res 2016;10:52-58

21 Verdel N, Jerman I, Krasovec R, Bukovec P, Zupancic M. Possible time-dependent effect of ions and hydrophilic surfaces on the electrical conductivity of aqueous solutions. Int J Mol Sci 2012; 13:4048-4068

22 Boiron J, Cier A, VIngert C. Effets de quelques facteurs physiques sur l'activité pharmacologique de dilutions infinitésimales. Ann Homeopath Fr 1968;10:187-196

23 Witt CM, Lüdtke R, Weisshuhn TE, Quint P, Willich SN. The role of trace elements in homeopathic preparations and the influence of container material, storage duration, and potentisation. Forsch Komplement Med 2006;13:15-21

24 Ive EC, Couchman IM, Reddy L. Therapeutic effect of Arsenicum album on leukocytes. Int J Mol Sci 2012;13:3979-3987

25 de Santana FR, Dalboni LC, Nascimento KF, et al. High dilutions of antimony modulate cytokines production and macrophage Leishmania (L.) amazonensis interaction in vitro. Cytokine 2017;92:33-47

26 Wynn TA, Chawla A, Pollard JW. Macrophage biology in development, homeostasis and disease. Nature 2013;496:445-455

27 Marzotto M, Bonafini C, Olioso D, et al. Arnica montana stimulates extracellular matrix gene expression in a macrophage cell line differentiated to wound-healing phenotype. PLoS One 2016;11: e0166340

28 Brazilian Homeopathic Pharmacopoeia. 3rd ed, Brazil: Ministerio da Saúde 2011, pp 34. Available at: http://portal.anvisa.gov.br/ documents/33832/259147/Farmacopeia+HOMEOPATICA+3a+EDICAO+INGLES+com+alerta.pdf/49a48a50-0d3e-4ab9-bc41eb361c8afbb1

29 Verdel N, Jerman I, Krasovec R, Bukovec P, Zupancic M. Possible time-dependent effect of ions and hydrophilic surfaces on the 
electrical conductivity of aqueous solutions. Int J Mol Sci 2012; 13:4048-4068

30 Bach C, Dauchy X, Severin I, Munoz JF, Etienne S, Chagnon MC. Effect of temperature on the release of intentionally and nonintentionally added substances from polyethylene terephthalate (PET) bottles into water: chemical analysis and potential toxicity. Food Chem 2013;139:672-680

31 Grotenhuis N, De Witte SF, van Osch GJ, Bayon Y, Lange JF, Bastiaansen-Jenniskens YM. Biomaterials influence macrophage-mesenchymal stem cell interaction in vitro. Tissue Eng Part A 2016;22:1098-1107

32 Grotenhuis N, Vd Toom HFE, Kops N, et al. In vitro model to study the biomaterial-dependent reaction of macrophages in an inflammatory environment. Br J Surg 2014;101:983-992

33 Bell IR, Muralidharan S, Schwartz GE. Nanoparticle characterization of traditional homeopathically - manufactured Gelsemium sempervirens medicines and placebo controls. J Nanomedicine Biotherapeutic Discov 2015;5:1-13

34 Demangeat JL. Gas nanobubbles and aqueous nanostructures: the crucial role of dynamization. Homeopathy 2015;104:101-115

35 Jäger T, Scherr C, Wolf U, Simon M, Heusser P, Baumgartner S. Investigation of arsenic-stressed yeast (Saccharomyces cerevisiae) as a bioassay in homeopathic basic research. Sci World J 2011;11:568-583

36 Olioso D, Marzotto M, Bonafini C, Brizzi M, Bellavite P. Arnica montana effects on gene expression in a human macrophage cell line. Evaluation by quantitative Real-Time PCR. Homeopathy 2016;105:131-147

37 Mondal J, Das J, Shah R, Khuda-Bukhsh AR. A homeopathic nosode, Hepatitis $C 30$ demonstrates anticancer effect against liver cancer cells in vitro by modulating telomerase and topoisomerase II activities as also by promoting apoptosis via intrinsic mitochondrial pathway. J Integr Med 2016; 14:209-218

38 Mukherjee S, Ray M, Dutta MK, Acharya A, Mukhopadhyay SK, Ray S. Morphological alteration, lysosomal membrane fragility and apoptosis of the cells of Indian freshwater sponge exposed to washing soda (sodium carbonate). Ecotoxicol Environ Saf 2015; 122:331-342
39 Köpf-Maier P. The phosphorus content of lysosomes in hepatocytes and Kupffer cells. A study using electron-spectroscopic imaging. Acta Anat (Basel) 1990;139:164-172

40 Kao JK, Wang SC, Ho LW, et al. Chronic iron overload results in impaired bacterial killing of THP-1 derived macrophage through the inhibition of lysosomal acidification. PLoS One 2016;11:e0156713

41 Temgire MK, Suresh AK, Kane SG, Bellare JR. Establishing the interfacial nano-structure and elemental composition of homeopathic medicines based on inorganic salts: a scientific approach. Homeopathy 2016;105:160-172

42 Chikramane PS, Suresh AK, Kane SG, Bellare JR. Metal nanoparticle induced hormetic activation: a novel mechanism of homeopathic medicines. Homeopathy 2017;106:135-144

43 Ullman D. Let's have a serious discussion of nanopharmacology and homeopathy. FASEB J 2006;20:2661, author reply 2662

44 Cartwright SJ. Solvatochromic dyes detect the presence of homeopathic potencies. Homeopathy 2016;105:55-65

45 Cartwright SJ. Interaction of homeopathic potencies with the water soluble solvatochromic dye bis-dimethylaminofuchsone. Part 1: pH studies. Homeopathy 2017;106:37-46

46 Cartwright SJ. Degree of response to homeopathic potencies correlates with dipole moment size in molecular detectors: implications for understanding the fundamental nature of serially diluted and succussed solutions. Homeopathy 2018;107:19-31

47 Ynnon T. Very dilute aqueous solutions - structural and electromagnetic phenomena. Water 2017;9:28-66

48 Klein SD, Würtenberger S, Wolf U, Baumgartner S, Tournier A. Physicochemical investigations of homeopathic preparations: a systematic review and bibliometric analysis-Part 1. J Altern Complement Med 2018;24:409-421

49 Pollack GH. The Fourth Phase of Water - Beyond Solid, Liquid, and Vapor. Seattle: Ebner \& Sons Publishers; 2013:357

50 Bellavite P, Signorini A. The Emerging Science of Homeopathy. Complexity, Biodynamics and Nanopharmacology, 1st ed. Berkeley, CA: North Atlantic Books; 2002:409

51 Guedes JRP, Bonamin LV, Capelozzi VL. Water-related mechanisms proposed for storing and transmitting homeopathic information: putative links with biological responses. Homeopathy 2018; 107:172-180 